\title{
Dimensional stabilisation of Scots pine (Pinus sylvestris L.) sapwood by reaction with maleic anhydride and sodium hypophosphite
}

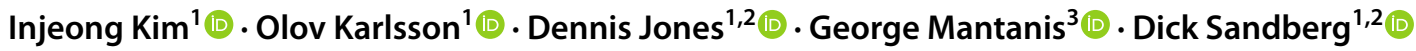

Received: 7 October 2020 / Accepted: 12 December 2020 / Published online: 3 January 2021

(c) The Author(s) 2021

\begin{abstract}
Wood has the ability to absorb and desorb moisture, which can affect its dimensional size when in use. Limiting this can provide products with greater shape stability and less stresses on external coatings. One method that has been investigated for achieving this has been through chemical modification. In this work, the dimensional stabilisation imparted to Scots pine sapwood by chemical modification with maleic anhydride (MA) combined with sodium hypophosphite (SHP) was investigated. The influence of concentration of MA, treatment temperature and treatment period on weight percent gain (WPG) and bulking coefficient (BC) during treatment with MA and SHP of wood was studied. Furthermore, dimensional stability was determined by the water soak/oven dry method (wet-dry cycle) through five cycles in order to determine the hydrolytic stability of the ester bond and any potential cross-linking reactions. Wood blocks $(20 \times 20 \times 10 \mathrm{~mm})$ modified with MA combined with SHP exhibited lower weight loss following water soaking than unmodified blocks or MA-treated blocks. Wood blocks modified with MA and SHP showed the best anti-swelling efficiency and minimum wet-volume (watersaturated). However, as the concentration of SHP increased, dimensional stability was diminished without any increase in weight percentage gain after water soaking. When combined with FTIR results, it appeared that the modification with MA and SHP seemed to form cross-linking between wood constituents, though high concentration of SHP did not seem to result in additional cross-linking.
\end{abstract}

\section{Introduction}

Scots pine (Pinus sylvestris L.) is a predominant wood species in Scandinavian forests. However, due to poor natural durability of its sapwood, it is difficult to use outdoors without any additional treatment. Since Scots pine sapwood has very good permeability (Terziev 2002; Terziev and Daniel 2002), it may be fully or partially impregnated with preservatives, mainly conventional wood preservatives based on copper and azoles, or CCA preservatives, to improve its

Injeong Kim

injeong.kim@1tu.se

1 Wood Science and Engineering, Luleå University of Technology, Forskargatan 1, 93187 Skellefteå, Sweden

2 Department of Wood Processing and Biomaterials, Faculty of Forestry and Wood Sciences, Czech University of Life Sciences Prague, Kamýcká 129, Suchdol, 16521 Praha 6, Czech Republic

3 Department of Forestry, Wood Sciences and Design, Laboratory of Wood Science and Technology, University of Thessaly, 43100 Karditsa, Greece durability. However, some of the substances in modern preservatives, such as copper, azoles, and boron, are known to be relatively safer and much less harmful than substances used in the past, such as mercury, creosote, pentachlorophenol and arsenic, which are harmful to mankind and the natural environment (Kamden et al. 2020). Since 1998, there have been more stringent rules regarding the registration and use of wood preservatives with known biocidal properties (OJEU 1998), which were later legitimised (European Parliament 2012), meaning that registration of such compounds is very expensive. Therefore, methods for achieving sustainable protection of wood have become more popular.

Wood modification can provide sustainable wooden products with high dimensional stability, whereby moisture interactions are reduced, which can potentially increase resistance to microbiological degradation without the need of using biocides. Active chemical modifications generally involve the chemical reaction between the reagent and hydroxyl groups within wood cell wall components. The formation of a chemical bond between the wood and reagent can thereby reduce the number of accessible hydroxyl groups and increase bulking of the cell wall, resulting in a 
reduction in moisture uptake, an increase in dimensional stability and enhanced durability of wood (Hill 2006). In addition to the reduction in moisture uptake, bulking of the cell wall can result in a permanently swollen wood structure, so negating the shrinkage and swelling mechanisms. The use of permanently swollen wood can be a benefit when used in conditions where there is an increased risk due to exposure to high moisture levels, such as when used outdoors in Use Class 3.1 and 3.2 situations. The stability of the wood substrate is beneficial for achieving suitably long service lives for surface coatings, since they will be less prone to stresses from dimensionally unstable wood, i.e., coatings on modified wood are often less likely to crack (Rowell and Bongers 2017). Thus, bulking of the cell wall and loss of hydrophilic hydroxyl groups reduce the moisture uptake, and increase the resistance to swelling and the decay of wood (Hill and Jones 1996; Hill 2006).

In contrast to linear anhydrides such as acetic anhydride, the modification of wood with cyclic anhydrides results in the formation of ester bonds with accessible hydroxyl groups in wood components without any undesired by-product, such that the resulting wood carboxylic moieties are capable of undergoing further reaction (Hill and Mallon 1998). For these reasons, the reaction between wood and cyclic anhydrides and various subsequent reactions have been extensively studied (Hill and Mallon 1998; Li et al. 2011; Matsuda 1987, 1993; Matsuda et al. 1988), with maleic, succinic, and phthalic anhydride being the main reagents studied. For these chemicals to penetrate into wood cell walls, an organic solvent is required as a solvent to dissolve the reagent and to swell the cell wall, and therefore systems containing pyridine, dimethyl-formamide (DMF) or xylene have been used (Evans 1998; Hill and Mallon 1998; Suttie et al. 1998; Yildiz et al. 2005).

In previous studies, maleic anhydride (MA) has been used more as crosslinking agent between wood and chemicals added for subsequent reactions than as a direct modification agent of the wood constituents (Matsuda and Ueda 1985; Matsuda et al. 1988; Watanabe et al. 1991; Fujimoto 1992, 1995; Roussel et al. 2001; Essoua Essoua et al. 2015). Some studies showed that anti-swelling efficiency (ASE) as well as fungal resistance of wood can be improved by reaction with the MA or maleic acid (Matsuda et al. 1988; Itoh et al. 1999; Iwamoto and Ito 2005). However, some of the weight gained through treatment was lost during subsequent cyclic wet-dry measurements (Matsuda et al. 1988; Iwamoto and Ito 2005; Essoua Essoua et al. 2015), which indicated that the bond between MA and wood is susceptible to hydrolysis.

In studies of cotton cellulose, it was suggested that sodium hypophosphite (SHP) may react with the unsaturated sites on maleic acid modified cellulose to form a crosslink (Fig. 1) resulting in better properties in terms of wrinkle resistance and fire properties after laundry cycles (Wu and Yang 2008; Hamed et al. 2016). The treatment with SHP improved breaking strength and tearing strength of cotton esterified with maleic acid (Peng et al. 2012). Cellulose nanofibril aerogels treated with MA and SHP showed improved wet stability through the formation of a crosslink (Kim et al. 2015).

Wood cellulose has a lower crystallinity than cotton, and wood also contains other accessible wood polymers (hemicellulose and lignin) as well as extractives. Thus, it is anticipated that such reactions can be expected to take place in MA-treated wood. Considering that this system has good wash resistance in cotton, it appears logical that there should be an improvement in the stability of the ester bond between wood and treated chemicals, which might enhance wood properties such as dimensional stability. Therefore, in this study, the possibility of modifying wood with MA and SHP was investigated.

\section{Materials and methods}

\subsection{Materials}

Scots pine (Pinus sylvestris L.) sapwood was cut into a dimension of $20 \times 20 \times 10(\mathrm{R} \times \mathrm{T} \times \mathrm{L}) \mathrm{mm}$ and extracted with acetone:water (4:1) using a Soxhlet apparatus for $6 \mathrm{~h}$ and oven-dried at $103{ }^{\circ} \mathrm{C}$ for $16 \mathrm{~h}$. Five replicates per each treatment (along with reference samples) were prepared.

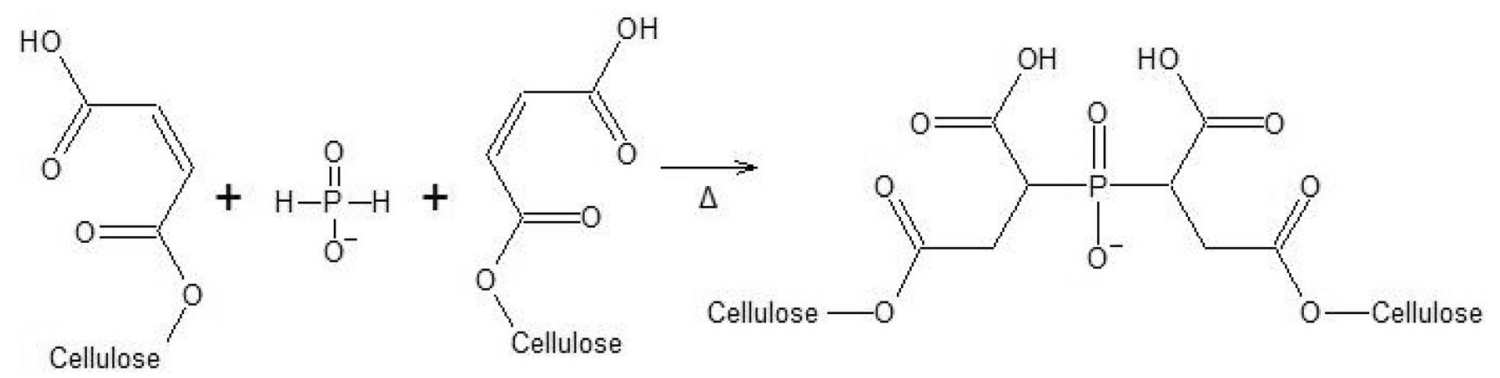

Fig. 1 Scheme of reaction between maleic anhydride (MA) treated cotton cellulose and sodium hypophosphite (Yang et al. 2010) 
Specimens were stored in a desiccator over silica gel prior to modification.

Maleic anhydride (MA) (CAS No. 108-31-6) for synthesis was purchased from Sigma Aldrich and sodium hypophosphite monohydrate 98\% (CAS No. 7681-53-0) from Alfa Aesar. Distilled water was purchased from Brenntag Nordic $\mathrm{AB}$ and technical grade acetone from VWR Chemicals.

\subsection{Development of method}

Prior to this study, the choice of treatment methods and solvent for each reagent, MA and SHP, was evaluated as follows. When MA was dissolved in water, $\mathrm{pH}$ was found to drop rather quickly below $\mathrm{pH} 1$, as MA hydrolysed into maleic acid, due to it having a $\mathrm{pK}_{\mathrm{a} 1}$ of 1.5 (Musa 2016). To avoid a strong acid environment during treatment, it was decided to use an organic solvent for MA. From this range of solvents, acetone was selected because it does not react with MA, can dissolve up to $70 \mathrm{wt} \%$ of MA at room temperature (Musa 2016) and can also penetrate into the wood fibre resulting in swelling (Mantanis et al. 1994). Other swelling solvents like DMSO and pyridine were excluded due to the possibility of unwanted reaction, for example DMSO might react with MA resulting in a Pummerer addition reaction (Rajput et al. 2011), often noted by a resulting pink colouration to the liquid, whilst pyridine can initialize homopolymerisation of MA (Wiley 1986). However, whilst SHP is easy to dissolve in water, it is insoluble in acetone. Therefore, in this study, a two-step process was chosen, in which wood was first treated with MA in acetone, followed by an aqueous solution of SHP.

\subsection{Esterification of wood with maleic anhydride}

To investigate the optimum conditions for MA treatment, specimens dried at $103{ }^{\circ} \mathrm{C}$ were treated with MA at various concentrations, curing temperatures and time periods to produce maleated wood. For each condition, five specimens were pressure-impregnated in MA solution in acetone at 12 bar for $2 \mathrm{~h}$, ensuring samples remained immersed throughout the impregnation period. Impregnated specimens were heated in the oven for the reaction between MA and wood and allowed to cool at room temperature. All MAtreated specimens were extracted with acetone using Soxhlet apparatus for $6 \mathrm{~h}$ to remove any excess MA, followed by oven drying at $103{ }^{\circ} \mathrm{C}$ for $16 \mathrm{~h}$. Oven-dried dimensions of specimens were measured using a calliper to calculate bulking coefficient (BC), and oven dried weights were measured to calculate weight percentage gain (WPG) caused by the treatment. WPG and BC were calculated according to wellknown formula (Mohtar et al. 2014). WPG was calculated using:
$W P G=100 \times \frac{W_{t}-W_{0}}{W_{0}}$,

where $\mathrm{W}_{0}$ is the oven-dried weight of specimens before treatment and $\mathrm{W}_{t}$ is the oven-dried weight of specimens after treatment.

$\mathrm{BC}$ was calculated using:

$B C=100 \times \frac{V_{t}-V_{0}}{V_{0}}$,

where $\mathrm{V}_{0}$ is the oven-dried volume of specimens before treatment and $V_{t}$ is the oven-dried volume of specimens after treatment.

To avoid confusion between maleated specimens and specimens treated with both MA and SHP, the WPG and BC of maleated specimens are written $\mathrm{WPG}(\mathrm{mal})$ and $\mathrm{BC}(\mathrm{mal})$.

\subsection{Treatment with sodium hypophosphite}

To investigate the influence of SHP on MA-treated wood and optimum condition for SHP treatment, specimens treated with MA were further treated with SHP at different concentrations, curing temperatures and time periods. Prior to SHP treatment, all specimens were impregnated with $3.5 \mathrm{M} \mathrm{MA}$ solution, heated at $115{ }^{\circ} \mathrm{C}$ for $2 \mathrm{~h}$, allowed to cool to room temperature and extracted with acetone by Soxhlet apparatus as described above. This particular condition was chosen based on the WPG and BC results shown in Figs. 2 and 3 from treatments described in Sect. 2.2.

Specimens were impregnated in aqueous solution of SHP for 30 min under pressure, followed by heating in the oven for the reaction between MA-treated wood and SHP. To remove excess SHP, specimens were treated with distilled water for 40 min under reduced pressure, followed by soaking under water for $72 \mathrm{~h}$. To facilitate further leaching, water was replaced every $24 \mathrm{~h}$. Afterwards, all specimens were air-dried in a fume hood for a period of $48 \mathrm{~h}$, followed by heating at $103{ }^{\circ} \mathrm{C}$ for a further $24 \mathrm{~h}$. The oven-dried weights and dimensions of treated wood specimens were measured to calculate WPG and BC. All treated specimens were placed in a vacuum desiccator with silica to minimise moisture uptake from air prior to wet-dry cycles.

\subsection{Dimensional stability test}

To investigate dimensional stability of specimens, all specimens including references (untreated) were subjected to repeated wet-dry cycles. Specimens were vacuum-impregnated in distilled water for 1 hour, followed by soaking under water for $72 \mathrm{~h}$. Water was replaced every $24 \mathrm{~h}$ without drying 
Fig. 2 Weight percentage gain (WPG) and bulking coefficient (BC) of wood by treatment with different molar concentrations of maleic anhydride in acetone
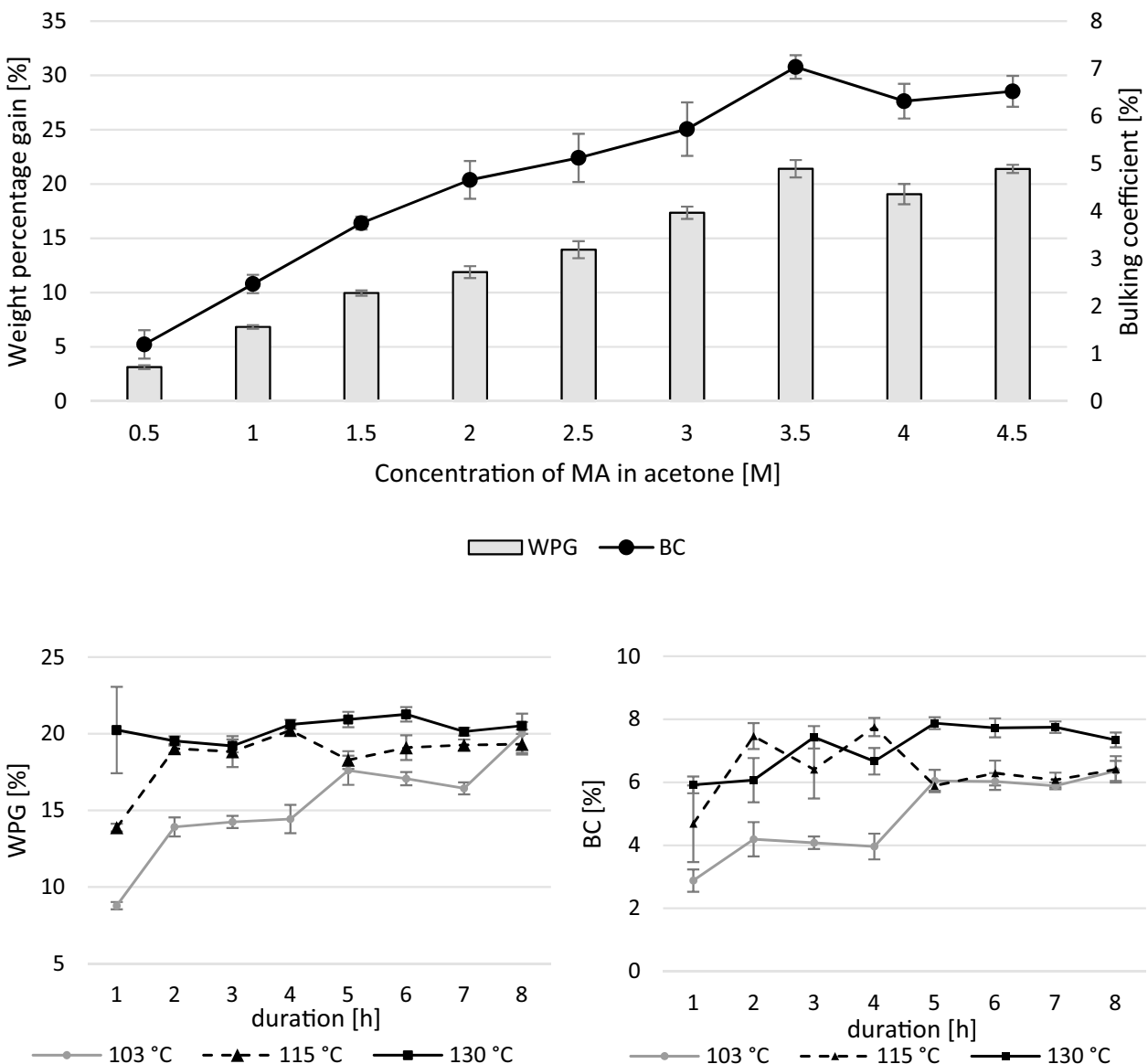

Fig. 3 Weight percentage gain (WPG) and bulking coefficient (BC) of specimens treated with $3.5 \mathrm{M}$ of maleic anhydride solution in acetone due to curing period and treatment temperature in between. The volumetric swelling coefficient $(\mathrm{S})$ and antiswelling efficiency (ASE) were calculated according to the well-known formulas (Stamm 1964). Afterwards, all specimens were air-dried in a fume hood for a period of $48 \mathrm{~h}$, followed by heating at $103{ }^{\circ} \mathrm{C}$ for a further $24 \mathrm{~h}$. Oven-dried weights and dimensions were measured to calculate WPG and $\mathrm{BC}$.

This wet-dry cycle was repeated five times. To investigate the formation of cross-linking, the volumetric change $(\Delta \mathrm{A})$ was calculated:

$\Delta \mathrm{A}=100 \times \frac{V_{D n}-V_{0}}{V_{0}}$,

where $V_{\text {Dn }}$ is oven-dried volume of specimen after nth wetdry cycle and $V_{0}$ is oven-dried volume of specimen before modification.

\subsection{FTIR study}

The formation of ester bond by reaction of wood with MA and reduction of double bond in MA-treated wood by SHP were studied in treated specimen with Fourier-transform infrared spectroscopy (FTIR). A small scrape made from a tangential surface of specimens was studied with FTIR (ZnSe/Diamond ATR crystal, DTGS detector, $4000-600 \mathrm{~cm}^{-1}, 10$ scans). To identify esterification, bands at $1723 \mathrm{~cm}^{-1}$ and $1163-1210 \mathrm{~cm}^{-1}$ were studied, while the band observed at $1635 \mathrm{~cm}^{-1}$ was used to identify reaction of double bond in MA-treated wood caused by SHP.

\section{Results and discussion}

The WPG( $\mathrm{mal})$ and $\mathrm{BC}(\mathrm{mal})$ of specimens treated with different concentrations of solution are shown in Fig. 2. The $\mathrm{WPG}(\mathrm{mal})$ and $\mathrm{BC}(\mathrm{mal})$ increased as the concentration of maleic anhydride in solution increased up to $3.5 \mathrm{M}$. However, at a concentration between 3.5 and $4.5 \mathrm{M}$, the values of WPG and BC did not show any significant difference (Fig. 2).

The treatment temperature seemed to influence the extent of esterification of MA with wood. Increase in WPG(mal) and BC(mal) of MA-impregnated specimens treated at $103{ }^{\circ} \mathrm{C}$ was low at short treatment periods but increased with the treatment period up to $5 \mathrm{~h}$, thereafter results remained constant (Fig. 3). On the other hand, by 
using a treatment temperature of $130{ }^{\circ} \mathrm{C}$, high WPG $($ mal $)$ and $\mathrm{BC}(\mathrm{mal})$ were obtained for a treatment period of 1 hour. Further treatment at the higher temperature did not show any significant difference in terms of WPG $(\mathrm{mal})$, although a higher $\mathrm{BC}(\mathrm{mal})$ seemed to stabilise at longer treatment periods. To achieve equivalent $\mathrm{WPG}(\mathrm{mal})$ and $\mathrm{BC}(\mathrm{mal})$ to those specimens treated previously at $130{ }^{\circ} \mathrm{C}$, reaction times of at least $2 \mathrm{~h}$ at $115^{\circ} \mathrm{C}$ or $5 \mathrm{~h}$ at $103{ }^{\circ} \mathrm{C}$, respectively, were required (Fig. 3 ).

The WPG of specimens was lower after treatment with SHP than specimens treated with only MA. Furthermore, the WPG and BC of specimens increased with increased temperature and time of the treatment (Fig. 4) despite the higher reaction temperatures increasing the likelihood of thermal degradation. Furthermore, hydrolysis of the ester bonds is favoured in the presence of water and acid conditions; on the contrary, condensation may be favoured by lower water content. The latter conditions may exist for a longer treatment time at $130{ }^{\circ} \mathrm{C}$. These results indicate that the hydrolysis of the ester bond is dominant at the beginning of the reaction, and a temperature above $130{ }^{\circ} \mathrm{C}$ is needed for sufficient cross-linking reactions to occur.

The increase in WPG, however, did not correlate with the increase in concentration of SHP in the impregnation solution. The MA-treated specimens without SHP had the highest WPG after corresponding heat treatment, though the WPG decreased rapidly during subsequent wet-dry cycles (Fig. 5). Specimens treated with both MA and SHP showed less WPG compared to those without SHP treatment. However, the weight loss by wet-dry cycles was decreased; the specimens treated with $0.25 \mathrm{M}$ and $0.5 \mathrm{M}$ SHP did not show significant differences in WPGs between each cycle. However, as the concentration of SHP in the treatment solution increased, the stability noted during wet-dry cycles decreased (Fig. 5).

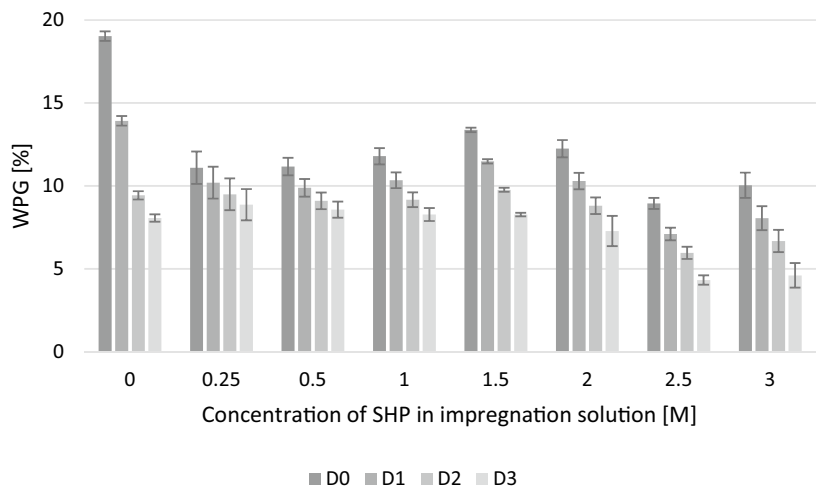

Fig. 5 Weight percentage gain (WPG) [\%] of maleated specimens treated with different concentrations of sodium hypophosphite (SHP) during wet-dry cycle; Dn, oven-dried in the nth cycle

The tendency of weight stability during wet-dry cycles (Fig. 6) displayed similarities in dimensional stabilities of specimens shown in Table 1. The specimens treated with $0.5 \mathrm{M}$ SHP showed the best anti-swelling efficiency (ASE) even after extended water soaking treatments. The specimens treated with $0.5 \mathrm{M}$ SHP showed improved ASE due to larger oven-dried dimensions (bulking effect through modification) as well as having smaller wet-dimensions corresponding to moisture content well above fibre saturation point (FSP) compared to untreated as well as other treatments shown in Fig. 6. The results can be considered as evidence of stable cross-linking (Hill 2006). Considering that the WPG of these specimens was lower than the ones only treated with MA (Fig. 5), the combined treatment seemed to improve the dimensional stability efficiently. However, the treatment with a high concentration of SHP seemed to worsen the dimensional stability compared to the treatment with low concentration; not only the ASEs were decreased
Fig. 4 Weight percentage gain (WPG) [\%] and bulking coefficient (BC) [\%] of specimens treated with $3.5 \mathrm{M}$ maleic anhydride at $115^{\circ} \mathrm{C}$ for $2 \mathrm{~h}$ and $0.5 \mathrm{M}$ sodium hypophosphite (SHP) solution as a function of duration $t$ and temperature

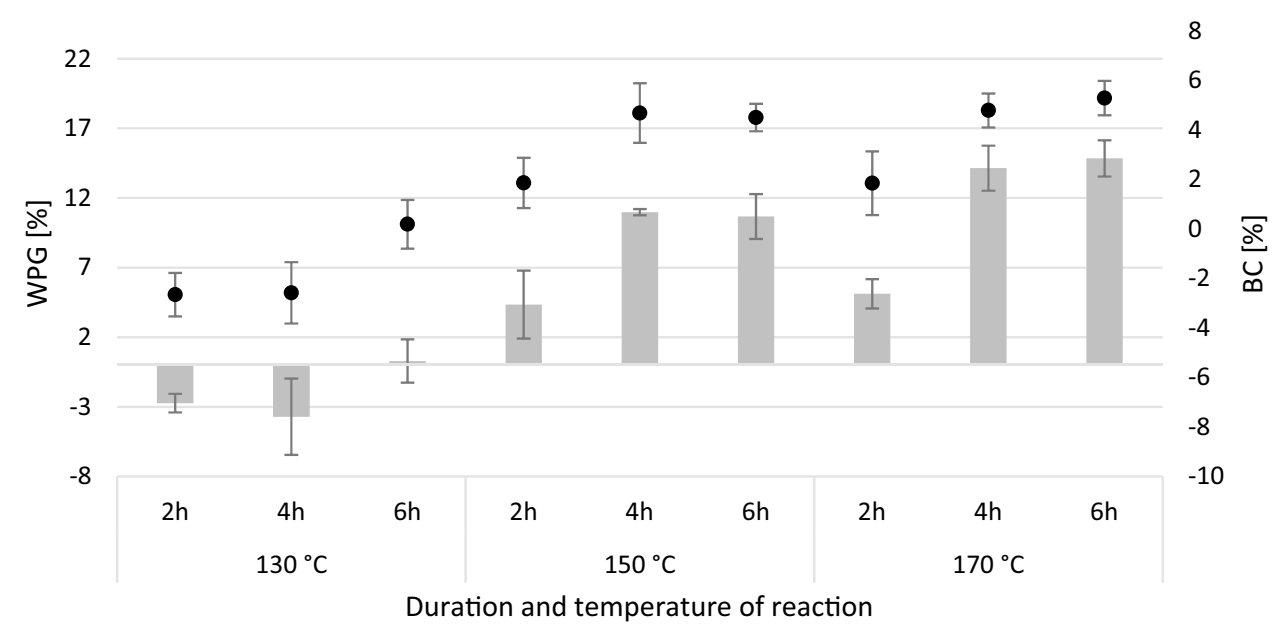

$\square$ WPG $\bullet B C$ 
Table 1 Anti-swelling efficiency (ASE) [\%] of specimens treated with 3.5 M maleic anhydride solution followed by sodium hypophosphite (SHP) in different concentrations

\begin{tabular}{lllllllr}
\hline \multicolumn{7}{c}{ Concentration of SHP in solution $[\mathrm{M}]$} \\
\cline { 2 - 8 } & 0 & 0.5 & 1 & 1.5 & 2 & 2.5 & \multicolumn{1}{l}{3} \\
\hline 1st cycle & $31.9(1.62)$ & $58.2(4.75)$ & $41.8(3.58)$ & $25.5(1.56)$ & $24.6(7.09)$ & $19.5(4.42)$ & $2.8(3.09)$ \\
2nd cycle & $33.7(3.05)$ & $53.2(2.99)$ & $43.6(3.58)$ & $22(1.66)$ & $14.1(5.08)$ & $12.6(4.19)$ & $6.6(4.53)$ \\
3rd cycle & $26.2(2.91)$ & $55.5(4.83)$ & $43.6(3.52)$ & $29.7(1.57)$ & $20.7(6.7)$ & $22.0(3.39)$ & $16.3(3.05)$ \\
4th cycle & $21.9(2.47)$ & $56.4(3.35)$ & $42.5(2.13)$ & $24.7(2.22)$ & $17.4(5.27)$ & $17.5(3.75)$ & $9.8(5.50)$ \\
5th cycle & $14.8(2.83)$ & $50.7(2.07)$ & $38.4(2.75)$ & $19.0(2.13)$ & $19.5(2.04)$ & $13.4(2.71)$ & $10.4(3.43)$ \\
\hline
\end{tabular}

Values in parentheses are standard deviation

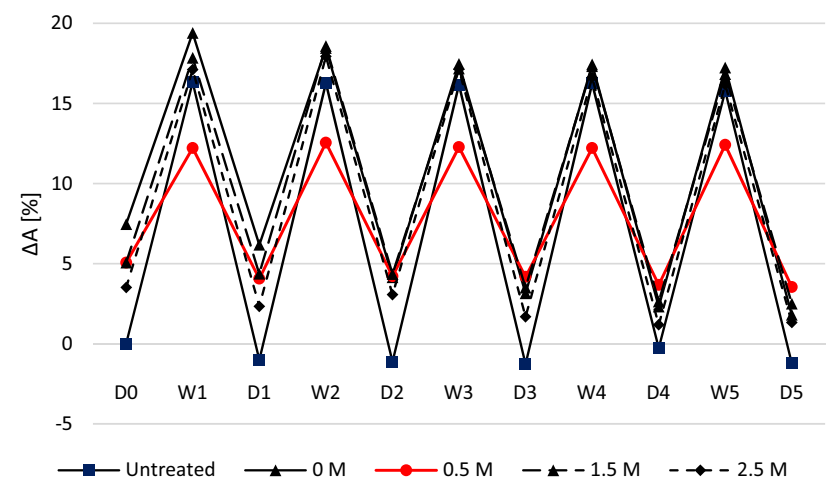

Fig. 6 Volumetric changes $(\Delta \mathrm{A})$ of specimens untreated and treated with maleic anhydride and different concentrations of sodium hypophosphite (SHP) during wet-dry cycle; Dn, oven-dried in the nth cycle; $\mathrm{Wn}$, wet in the nth cycle

as the concentration of SHP was increased (Table 1), but also the maximum dimension of wet state increased (Fig. 6). Kim et al. (2019) showed in a study of treatments using methanol to model the formation of cross-linking reactions in wood that the formed reaction product depended on the content of SHP.

The FTIR spectra of maleated specimens showed an increased band around $1730 \mathrm{~cm}^{-1}$ compared to untreated specimens, which indicated the formation of an ester bond. The decrease in the peak at $1640 \mathrm{~cm}^{-1}$, which was formed after treatment with MA, was observed after treatment with SHP, which might be due to a reaction with $\mathrm{C}=\mathrm{C}$ bond in maleated wood. A similar tendency was observed in the study by Yang et al. (2010), where cotton cellulose reacting with MA and SHP was studied. Differences at $1200-1300 \mathrm{~cm}^{-1}$ for treatment with $0.5 \%$ and other concentrations of SHP could be observed (Fig. 7).

\section{Conclusion}

An investigation into the effect of modifying wood with maleic anhydride (MA) and sodium hypophosphite (SHP) on the dimensional stability of wood has been performed.

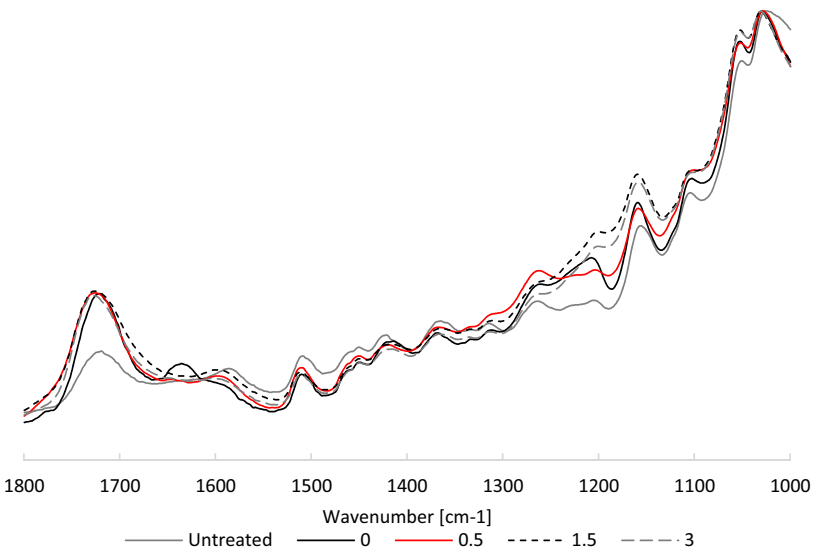

Fig. 7 FTIR spectra of specimens, untreated and maleated specimens treated with different molar concentrations of sodium hypophosphite (SHP) solution (0-3 M)

Wood treated with MA and SHP showed better antiswelling efficiency (ASE), lower weight loss and smaller saturated volumes than untreated or MA-treated specimens during wet-dry cycling. Results suggest that treatments with relatively low amounts of SHP can be used to achieve good stability of the modified wood product. Hypothesising a cross-linking reaction together with a bulked cell wall can explain these observed effects. Since this treatment shows promising results on dimensional stability, there is a possibility for such treated wood to be used as a material for outdoor conditions, such as in Use Class 3.2.

Acknowledgements Financial support from the Swedish Innovation Agency (Vinnova Bioinnovation programme), project Swedish wood-innovation potential for the bio-based society-DP2: Needed processing of Swedish wood, 2017-02697, Financial support from the Swedish Research Council for Environment, Agricultural Sciences and Spatial Planning (FORMAS), project "Fungal growth on modified wood-based products under sub arctic conditions 2017-00419", is gratefully acknowledged. In addition, Dennis Jones and Dick Sandberg are grateful for the support of "Advanced research supporting the forestry and wood-processing sector's adaptation to global change and the 4th industrial revolution", OP RDE (Grant No. CZ.02.1.01/0.0/0. 0/16_019/0000803). 
Open Access This article is licensed under a Creative Commons Attribution 4.0 International License, which permits use, sharing, adaptation, distribution and reproduction in any medium or format, as long as you give appropriate credit to the original author(s) and the source, provide a link to the Creative Commons licence, and indicate if changes were made. The images or other third party material in this article are included in the article's Creative Commons licence, unless indicated otherwise in a credit line to the material. If material is not included in the article's Creative Commons licence and your intended use is not permitted by statutory regulation or exceeds the permitted use, you will need to obtain permission directly from the copyright holder. To view a copy of this licence, visit http://creativecommons.org/licenses/by/4.0/.

\section{References}

Essoua Essoua GG, Blanchet P, Landry V, Beauregard R (2015) Maleic anhydride treated wood: effects of drying time and esterification temperature on properties. BioRes 10(4):6830-6860

European Parliament (2012) Regulation (EU) No 528/2012 of the European Parliament and of the Council of 22 May 2012 concerning the making available on the market and use of biocidal products.\&nbsp;https://eur-lex.europa.eu/legal-content/EN/ TXT/?uri=CELEX\%3A32012R0528

Evans PD (1998) Weather resistance of wood esterified with dicarboxylic acid anhydrides. Holz Roh Werkst 56(5):294

Fujimoto H (1992) Weathering behaviour of chemically modified wood with maleic acid-glycerol (MG) mixture. FRI Bull 176:87-96

Fujimoto H (1995) Reaction conditions of maleic acid-glycerol treatment of solid wood. Rinsan Shikenjoho 9:1-6

Hameed S, Hussain MA, Masood R, Haseeb MT (2016) Cross-linking of cotton fabric using maleic anhydride and sodium hypophosphite. Cellulose Chem Technol 50(2):321-328

Hill CAS (2006) Wood modification-chemical, thermal and other processes.\&nbsp;Wiley Series in Renewable Resources. Wiley and Sons, Chichester

Hill CAS, Jones D (1996) The dimensional stabilisation of Corsican pine sapwood by reaction with carboxylic acid anhydrides. Holzforschung 50:457-462

Hill CAS, Mallon S (1998) The chemical modification of Scots pine with succinic anhydride or octenyl succinic anhydride. I. Dimensional stabilisation. Holzforschung 52(4):427-433

Itoh T, Kato K, Nishimura M (1998) Dimensional stability of wood treated with tricarboxylic acid (I). Treatment with carboxyethylthiosuccinic acid (in Japanese). Bull Nara Pref For Expt Sta 28:1-6

Iwamoto Y, Itoh T (2005) Vapor phase reaction of wood with maleic anhydride (I): dimensional stability and durability of treated wood. J Wood Sci 51:595-600

Kamden DP, Pascal N, Herman D, Shu Z (2020) Biological performance of a formulation containing water-dispersible copper naphthenate and sodium fluoride against decay fungi. Wood Mater Sci Eng 15(1):30-36

Kim CH, Youn HJ, Lee HL (2015) Preparation of cross-linked cellulose nanofibril aerogel with water absorbency and shape recovery. Cellulose 22:3715-3724. https://doi.org/10.1007/s10570-015-0745-5

Kim I, Karlsson O, Anzutkin O, Shah F, Jones D, Sandberg D (2019) Wood modification with maleic anhydride and sodium hypophosphite. In: Proceedings of the 20th International Symposium on Wood, Fiber and Pulping Chemistry, ISWFPC20, 2019, Tokyo, pp 1-4

Li Y, Dong X, Liu Y, Li J, Wang F (2011) Improvement of decay resistance of wood via combination treatment on wood cell wall: swellbonding with maleic anhydride and graft copolymerization with glycidyl methacrylate and methyl methacrylate. Int Biodeterior Biodegradation 65:1087-1094

Mantanis G, Young RA, Rowell RW (1994) Swelling of wood part II: swelling in organic liquids. Holzforschung 48:480-490

Masuda H (1993) Preparation and properties of oligoesterified wood blocks based on anhydride and epoxide. Wood Sci Technol 27:23-34

Matsuda H (1987) Preparation and utilization of esterified woods bearing carboxyl groups. Wood Sci Technol 21:75-88

Matsuda H, Ueda M (1985) Preparation and utilization of esterified wood bearing carboxyl groups (V). Addition reaction of esterified wood with epoxide and oligoesterification of the adducts obtained. Mokuzai Gakkaishi 31:267-273

Matsuda H, Ueda M, Murakami K (1988) Oligoesterified woods based on anhydride and epoxide (I). Preparation and dimensional stability of oligoesterified woods by stepwise addition reactions (in Japanese). Mokuzai Gakkaishi 34:140-148

Mohtar MA, Hamid NH, Sahri MH (2014) Effect of Linear Chain Carboxylic Acid Anhydrides on Physical and Mechanical Properties of Rubber (Hevea brasiliensis), Acacia, (Acacia spp.), and Oil Palm (Tinnera spp.) Woods. J Composites 2014:1-10

Musa OM (2016) Handbook of maleic anhydride based materials. Syntheses, properties and applications. Springer international publishing, Switzerland

OJEC (1998) Directive 98/8/EC of the European parliament and of the Council of 16 February 1998 concerning the placing of biocidal products on the market. Off J European Comm. L123:1-63

Peng H, Yang CQ, Wang S (2012) Nonformaldehyde durable press finishing of cotton fabrics using the combination of maleic acid and sodium hypophosphite. Carbohydr Polym 87:491-499

Rajput RS, Singh A, Singh RK (2011) Diestrification and Biological study of Styrene Maleic Anhydride Copolymer with Alcohol and DMSO. Int J Chem Tech Research 3(1):441-447

Roussel C, Marchetti V, Lemor A, Wozniak E, Loubinoux B, Gérardin P (2001) Chemical modification of wood by polyglycerol/maleic anhydride treatment. Holzforschung 55:57-62

Rowell R, Bongers F (2017) Role of moisture in the failure of coatings in wood. Coatings 7(12):219. https://doi.org/10.3390/coati ngs7120219

Stamm AJ (1964) Wood and cellulose science. Ronald Press, New York

Suttie ED, Hill CAS, Jones D, Orsler RJ (1998) Chemically modified solid wood. I. The resistance to fungal attack. Mater Org 32(3):159-182

Terziev N (2002) Industrial kiln drying and its effect on microstructure, impregnation and properties of Scots pine timber impregnated for above ground use. Part 1. Effects of initial, final dryings and preservative on impregnation and timber quality. Holzforschung $56: 428-433$

Terziev N, Daniel G (2002) Industrial kiln drying and its effect on microstructure, impregnation and properties of Scots pine timber impregnated for above ground use. Part 2. Effect of drying on microstructure and some mechanical properties of Scots Pine wood. Holzforschung 56:434-439

Watanabe N, Sasaya T, Ozawa S, Uraki Y (1991) Acylation of cellulose with maleic acid-glycerine. Res Bull Exp For Hokkaido Univ 48:259-270

Wiley RH (1986) The pyridine/acetic anhydride initiated homopolymerization of maleic anhydride, maleic acid, and cyclopent-4-ene1,3-dione. J Polym Sci Part C: Polymer Letters 24:219-221

Wu X, Yang CQ (2008) Flame retardant finishing of cotton fleece fabric-part III: the combination of maleic acid and sodium hypophosphite. J Fire Sci 26:351-368

Yang CQ, Chen D, Guan J, He Q (2010) Cross-linking cotton cellulose by the combination of maleic acid and sodium hypophosphite. 1. Fabric wrinkle resistance. Ind Eng Chem Res 49:8325-8332 
Yildiz UC, Dizman E, Kalaycioglu H, Yildiz S, Temiz A, Gezer ED (2005) The effects of chemical modification on the physical and mechanical properties of particleboards produced from alder and spruce chips. Proc. 2nd European Conference on Wood Modification, Göttingen
Publisher's Note Springer Nature remains neutral with regard to jurisdictional claims in published maps and institutional affiliations. 